\title{
SEXUAL VIOLENCE AGAINST WOMEN AND CHILDREN IN CHINESE SOCIETIES
}

\author{
KO LING CHAN \\ University of Hong Kong
}

This article provides a comprehensive overview of the reported patterns of sexual violence against women and children in China. It reviews the prevalence of and risk factors for various types of sexual violence and discusses community knowledge and perceptions of these violent acts. It also critically examines three major problems of sexual violence research in China. First, the diversity of findings and study methods reported by surveys and criminal reports reflects the problems in obtaining accurate figures on the scope of the problem. Second, precautions must be taken in reading studies on Chinese culture-specific risk factors for domestic violence. Third, the study of culture-specific factors should not focus solely on cultural factors in a vacuum but rather, should examine traditional culture in the context of modern societies and consensus international standards of human rights. Recommendations for future research are also discussed.

Key words: sexual violence; Chinese; culture-specific risk factors; prevalence

SEXUAL VIOLENCE is widely considered to be both a violation of human rights and a public health problem. It occurs in a variety of cultures and in many social settings, including the community, workplace, school, and even home. It has been described a product of the imbalance of power in the context of gender, family, and social relationships. The number of victims, predominantly although not exclusively women and minors, will continue to mount if the social, legal, and health systems fail to find a means to offer effective protection. Moreover, the negative impact of sexual violence is not confined to the victims; it affects the well-being of entire communities. Apart from profound reproduc- tive and sexual health problems, including unwanted pregnancy and transmission of diseases (e.g., HIV), victims of sexual abuse may also experience mental health problems such as posttraumatic stress disorder (Krug, Dahlberg, Mercy, Zwi, \& Lozano, 2002).

This article provides a comprehensive review of sexual violence in China by analyzing the current literature on gender-based violence with a particular focus on sexual violence and assault in China, including Mainland China, Hong Kong, and Macau. The scope of the review covers literature in the form of journal articles and book chapters located in databases, including criminal justice abstracts, MEDLINE, PsycINFO, social

AUTHOR'S NOTE: The project was commissioned by the South African Medical Research Council. Correspondence concerning this article should be addressed to Dr. Ko Ling Chan, Department of Social Work and Social Administration, The University of Hong Kong, Pokfulam, Hong Kong SAR, China; e-mail: eklchan@hkucc.hku.hk. 
services abstracts, and sociological abstracts. Chinese publications were included based on a search of Chinese databases. Government documents, such as policy papers and research reports, were also reviewed. Supplementary information was collected through interviews with key informants, including scholars, government officials, and service providers from NGOs in Hong Kong, Shanghai, and Shenzhen. The article discusses the prevalence of and risk factors for various types of sexual violence. Accounts of community knowledge and perceptions of sexual violence are presented to show how cultural beliefs affect the reporting and help-seeking behavior of sexual violence victims. Recommendations for future research are made based on this review of the most current sexual violence research in China.

\section{DEFINITION OF SEXUAL VIOLENCE}

The terms rape, sexual assault, sexual abuse, and sexual violence have overlapping meanings, and they are often used interchangeably in reports and documents. According to the World Health Organization (WHO), sexual violence refers to

any sexual act, attempt to obtain a sexual act, unwanted sexual comments or advances, or acts to traffic, or otherwise directed, against a person's sexuality using coercion [i.e., psychological intimidation, physical force, or threats of harm], by any person regardless of their relationship to the victim, in any setting, including but not limited to home and work. (Krug et al., 2002)

The types of acts regarded as sexual violence vary from country to country. Basically, they include rape and unwanted sexual contact (disregarding the perpetrator's relationship with the victim), sexual abuse of individuals incapable of defending themselves (including adults and children who are mentally or physically disabled,), forced engagement in a relationship (including marriage or cohabitation), denial of the use of contraception or of protection from sexually transmitted diseases, forced abortion, forced prostitution, and acts against the sexual integrity of women (Krug et al., 2002).

A wide range of sexually violent acts can take place in different situations and contexts. This review covers rape within marriage or dating relationships, rape by strangers, unwanted sexual advances or sexual harassment, and the sexual abuse of children.

\section{SCOPE OF CHINESE SOCIETIES}

Broadly speaking, the Chinese population includes immigrants in Western and Asian societies, and those living in Mainland China, Hong Kong, Macau, and Taiwan. However, most Chinese live in predominantly Chinese societies such as those of Mainland China, Hong Kong, Macau, and Taiwan. These societies differ in terms of their sociopolitical-economic structure. In China, there are four municipalities (Beijing, Tianjin, Shanghai, and Chongqing), 23 provinces (Anhui, Fujian, Gansu, Guangdong, Guizhou, Hainan, http://www.gd.gov.cn/ index_e.asp Hebei,Heilongjiang, http://www.jl. gov.cn/ jlgov_6/index.jspHenan, Hubei, Hunan, Jiangsu, Jiangxi, Jilin, Liaoning, Qinghai, Shaanxi, http:/ / www.eng.yn. gov.cn/Shandong, Shanxi, Sichuan, Taiwan, Yunnan, and http://www. gzgov.gov.cn/enggov/Zhejiang), five autonomous regions (Guangxi Zhuang, Inner Mongolia, Ningxia Hui, Tibet, and http:/ / www.gxi.gov.cn /English/Xinjiang Uygur), and two special administrative regions (Hong Kong and Macau). This article reviews studies of sexual violence specifically in Mainland China, Hong Kong, and Macau. Hong Kong and Macau, both of which were colonies for many years, are very much alike. Chinese people in Hong Kong and Macau are exposed to both Chinese and Western cultures, in particular those of the United States, the United Kingdom, and Portugal. The official language in Hong Kong is English, and even after the handover in 1997, English has remained the official language along with Chinese. The legal system in Hong Kong is basically adapted from the common law system of the United Kingdom, although it is now being integrated into the Mainland legal system. In Macau, Portuguese was the official language until the handover in 1999.

Significant cultural differences are to be found within Mainland China, which has more than 19 ethnic groups, the Han being the dominant group in terms of numbers (Chiu, 2001). Nearly $90 \%$ of

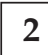


the population of Mainland China, Hong Kong, and Macau are Han Chinese. There are also huge differences between the people in rural areas and those in the cities, and between Northern and Southern China. In Southern China, regions such as the Pearl River Delta and Shanghai have a longer history of economic development and exposure to Western cultures. Chinese populations are indeed heterogeneous, and so caution should be exercised in interpreting findings from studies because no one study can represent all of the Chinese people in these societies.

\section{TYPES AND MAGNITUDE OF SEXUAL VIOLENCE IN CHINA}

\section{Sexual Violence in Spousal Relationships}

In general, estimates of the prevalence of spousal violence and victimization in Chinese societies range from $1.8 \%$ (Leung, $\mathrm{Ng}$, Leung, \& Ho, 2003) to 50\% (Yick, 1999). With regard to sexual violence in intimate relationships, estimates of the lifetime prevalence range from $5.8 \%$ to $16 \%$ for victimization and $7.3 \%$ for perpetration, whereas past-year prevalence figures range from $3.2 \%$ to $12 \%$ for victimization and $3.5 \%$ for perpetration (Chan, 2005; Leung, Leung, Lam, \& Ho, 1999; Liu \& Zhang, 2005; Xu et al., 2005). Table 1 presents a summary of studies published in English-language journals.

In a territory-wide cross-sectional study of 3,245 pregnant women recruited from seven hospitals in Hong Kong, approximately $2.5 \%$ of Chinese pregnant women had been physically or sexually abused (Chan, Tiwari, et al., 2008). In another population study of domestic violence conducted in Hong Kong, approximately $8.9 \%$ of women reported that they had experienced sexual coercion by their partner in their lifetime, and $4 \%$ said that an incident had occurred in the previous year (Chan, 2005). In the same study, the past-year prevalence of severe sexual violence against women, which was defined as involving use of a threat or force to obtain sex and was equivalent to spousal or marital rape, was $0.35 \%$. Thus, the estimated number of victims suffering spousal or marital rape is at least 6,000 women a year, a figure far higher than the number of cases reported to the Social Welfare Department of the
Government of Hong Kong, which in 2006 was 11. The huge gap between the number of cases known to the system and the figure revealed by the survey implies that the vast majority of victims do not report incidents, either to police or to social services. The existing mechanism for encouraging victims to report incidents is thus evidently ineffective. Considering the amount of resources now available for victims of sexual violence, the existing system would definitely become severely overloaded if it were to handle all of the unreported cases.

Most studies did not adequately address gender differences because they did not compare the rates of female and male victimization. In studies investigating the abuse experience of males and females (Chan, 2005), men also reported being victims of partner violence, although significant gender differences were observed, with women being the likely victims and men the likely perpetrators.

In Mainland China, some studies of sexual violence have been published in Chinese journals. Marital rape was reported to be one of the major reasons for family breakdown (Li, 2002). Another study comparing the prevalence of sexual violence against women by their partners in cities and rural areas indicated that approximately $8 \%$ of women in rural areas had experienced sexual abuse, considerably higher than the $2.8 \%$ reported by women in cities $(\mathrm{Si}, 2003)$.

\section{Sexual Violence Victimization and Sexual Harassment}

According to the $2002 \mathrm{WHO}$ report, the prevalence of sexual assault against women in Beijing over the preceding 5 years was 1.6\% (Krug et al., 2002). Approximately $25 \%$ of women reportedly had experienced various forms of sexual harassment, and $1 \%$ were coerced into sexual activities during their college years by teachers or peers (Tang, Yik, Cheung, Choi, \& Au, 1996).

In a household survey conducted in Hong Kong (Chan, 2005), female respondents were asked whether they had experienced sexual coercion outside marital relationships. The results indicated that nearly $1.6 \%$ of women had experienced sexual harassment in their life. Approximately $0.5 \%$ of women had been 
Table 1: Studies of the Prevalence of Spousal Sexual Violence in Chinese Societies, Published in English Journals

\begin{tabular}{|c|c|c|c|c|c|c|}
\hline Source & $\begin{array}{l}\text { Abuse } \\
\text { Type }\end{array}$ & Sample & Sampling & Measure & $\begin{array}{l}\text { Prevalence of } \\
\text { Sexual Violence }\end{array}$ & Risk Factors \\
\hline Chan (2005) & $\begin{array}{l}\text { Spousal } \\
\text { violence }\end{array}$ & $\begin{array}{l}5,049 \text { Chinese } \\
\text { couples in } \\
\text { Hong Kong, } \\
46.4 \% \text { male } \\
\text { and } 53.6 \% \\
\text { female } \\
\text { (response rate } \\
70 \% \text { ) }\end{array}$ & $\begin{array}{l}\text { Random } \\
\text { sample of } \\
\text { Hong Kong } \\
\text { households }\end{array}$ & $\begin{array}{l}\text { Questionnaire had } \\
\text { three main } \\
\text { components: } \\
\text { Demographic } \\
\text { questions } \\
\text { Revised Conflict } \\
\text { Tactic Scales } \\
\text { (CTS2; Straus } \\
\text { et al., 1996) for } \\
\text { data on spousal } \\
\text { violence } \\
\text { Personal and } \\
\text { Relationship } \\
\text { Profile (PRP; } \\
\text { Straus, Hamby, } \\
\text { Boney-McCoy, \& } \\
\text { Sugarman, 1999) } \\
\text { for data on } \\
\text { etiology }\end{array}$ & $\begin{array}{l}\text { Lifetime } \\
\text { prevalence: } \\
\text { Perpetration = } \\
7.28 \% \\
\text { Victimization = } \\
6.93 \% \\
\text { Annual } \\
\text { prevalence: } \\
\text { Perpetration = } \\
3.46 \% \\
\text { Victimization = } \\
3.24 \% \\
\text { Lifetime and } \\
\text { annual } \\
\text { prevalence of } \\
\text { female } \\
\text { victimization = } \\
8.9 \% \text { and } 4 \% \text {, } \\
\text { respectively }\end{array}$ & $\begin{array}{l}30 \text { significant risk factors identified, } \\
\text { including: } \\
\text { Face, in-law conflict, and most of } \\
\text { the PRP scales. } \\
\text { New arrival family and spousal age } \\
\text { difference }\end{array}$ \\
\hline $\begin{array}{l}\text { (Chan, } \\
\text { Tiwari, } \\
\text { et al. } \\
(2008)\end{array}$ & $\begin{array}{l}\text { Violence } \\
\text { against } \\
\text { pregnant } \\
\text { women }\end{array}$ & $\begin{array}{l}\text { 3,245 pregnant } \\
\text { women from } \\
\text { seven } \\
\text { hospitals in } \\
\text { Hong Kong }\end{array}$ & $\begin{array}{l}\text { Convenience } \\
\text { sampling }\end{array}$ & $\begin{array}{l}\text { Definition of abuse } \\
\text { by Abuse } \\
\text { Assessment } \\
\text { Screen (Soeken, } \\
\text { McFarlane, } \\
\text { Parker, \& } \\
\text { Lominack, 1998) }\end{array}$ & $\begin{array}{l}9 \% \text { of pregnant } \\
\text { women } \\
\text { abused by } \\
\text { partners in } \\
\text { preceding } \\
\text { year. } \\
2.5 \% \text { physically } \\
\text { or sexually } \\
\text { abused }\end{array}$ & $\begin{array}{l}\text { In-law conflict, low education level, } \\
\text { alcohol abuse, debt, receiving } \\
\text { social security, number of } \\
\text { children, unplanned pregnancy, } \\
\text { dependence on social support, } \\
\text { chronic illness }\end{array}$ \\
\hline $\begin{array}{l}\text { Leung, } \\
\text { Leung, } \\
\text { Lam, and } \\
\text { Ho (1999) }\end{array}$ & $\begin{array}{l}\text { Violence } \\
\text { against } \\
\text { pregnant } \\
\text { women }\end{array}$ & $\begin{array}{l}631 \text { Chinese } \\
\text { pregnant } \\
\text { women } \\
\text { attending } \\
\text { antenatal clinic } \\
\text { of local } \\
\text { teaching } \\
\text { hospital in } \\
\text { Hong Kong }\end{array}$ & $\begin{array}{l}\text { Convenience } \\
\text { sampling }\end{array}$ & $\begin{array}{l}\text { Definition of abuse } \\
\text { by Abuse } \\
\text { Assessment } \\
\text { Screen }\end{array}$ & $\begin{array}{l}9.4 \% \text { sexually } \\
\text { abused in the } \\
\text { past year }\end{array}$ & $\begin{array}{l}\text { Unplanned pregnancy } \\
\text { Unemployment of husband/partner }\end{array}$ \\
\hline $\begin{array}{l}\text { Liu and } \\
\text { Zhang } \\
\text { (2005) }\end{array}$ & $\begin{array}{l}\text { Spousal } \\
\text { violence }\end{array}$ & $\begin{array}{l}3,692 \text { Chinese } \\
\text { in } 3 \text { provinces } \\
\text { of China } \\
\text { ( } 31.4 \% \text { from } \\
\text { Zhejiang, } \\
33.3 \% \text { from } \\
\text { Hunan, } 35.3 \% \\
\text { from Gansu); } \\
50.05 \% \text { were } \\
\text { rural }\end{array}$ & $\begin{array}{l}\text { Convenience } \\
\text { sampling }\end{array}$ & $\begin{array}{l}\text { Family violence } \\
\text { defined by } \\
\text { Conflict Tactic } \\
\text { Scales (CTS; } \\
\text { Straus, 1979) }\end{array}$ & $\begin{array}{l}\text { Sexual abuse } \\
\text { against wives } \\
=5.8 \%\end{array}$ & $\begin{array}{l}\text { Causes of family violence: } \\
\text { Patriarchal ideology } \\
\text { Alcohol } \\
\text { Gambling } \\
\text { Extra-marital affairs } \\
\text { Poor quality of couple relationship } \\
\text { Men's poor control of anger } \\
\text { Lack of legislation to define family } \\
\text { violence as illegal } \\
\text { Gender inequality } \\
\text { Psychological disorders of abuser }\end{array}$ \\
\hline $\begin{array}{l}\text { (Xu, Zhu, } \\
\text { O'Campo, } \\
\text { Koenig, } \\
\text { Mock, and } \\
\text { Campbell } \\
(2005)\end{array}$ & $\begin{array}{c}\text { Violence } \\
\text { against } \\
\text { women }\end{array}$ & $\begin{array}{l}600 \text { Chinese } \\
\text { women } \\
\text { attending } \\
\text { outpatient } \\
\text { gynecological } \\
\text { clinic at major } \\
\text { teaching } \\
\text { hospital in } \\
\text { Fuzhou, } \\
\text { China, in } 2000\end{array}$ & $\begin{array}{l}\text { Random } \\
\text { selection of } \\
\text { patients } \\
\text { signing in } \\
\text { with nurse at } \\
\text { clinic }\end{array}$ & $\begin{array}{l}\text { Instrument } \\
\text { adapted from } \\
\text { WHO } \\
\text { Multicountry } \\
\text { Study on } \\
\text { Women's Health } \\
\text { and Life } \\
\text { Experiences } \\
\text { Questionnaire } \\
\text { (WHO, 2000) }\end{array}$ & $\begin{array}{l}\text { Lifetime } \\
\text { prevalence = } \\
16 \% \\
\text { Past year } \\
\text { prevalence }= \\
12 \%\end{array}$ & $\begin{array}{l}\text { Growing up in rural areas } \\
\text { Having two or more live-in partners } \\
\text { Having an unemployed partner } \\
\text { Being alcoholic (victim or partner) } \\
\text { Partner having extra-marital affair } \\
\text { Frequent quarreling with partner } \\
\text { Partner using illegal drugs } \\
\text { Socioeconomic and cultural risk } \\
\text { factors } \\
\text { Refusing job because of partner } \\
\text { Partner taking away or refusing to } \\
\text { give money } \\
\text { Believing in domestic authority } \\
\text { Believing there are good reasons } \\
\text { to beat a wife }\end{array}$ \\
\hline
\end{tabular}


Table 2: Prevalence of Familial Sexual Coercion in Hong Kong

\begin{tabular}{|c|c|c|c|c|c|c|}
\hline \multirow[b]{2}{*}{$\begin{array}{l}\text { Sexual Coercion } \\
\text { Incidents }\end{array}$} & \multirow[b]{2}{*}{ Happened $(\%)^{a}$} & \multirow{2}{*}{$\begin{array}{l}\text { Happened at } \\
\text { or Before } \\
\text { Age } 17(\%)\end{array}$} & \multicolumn{4}{|c|}{ Perpetrator of Sexual Coercion } \\
\hline & & & Family Members (\%) & $\begin{array}{l}\text { Relatives or } \\
\text { Friends (\%) }\end{array}$ & Strangers (\%) & Don't Know (\%) \\
\hline \multirow{2}{*}{$\begin{array}{l}\text { Forced to touch } \\
\text { someone or being } \\
\text { touched in a sexual way }\end{array}$} & \multirow[t]{2}{*}{1.6} & Yes $=61.8$ & 23.8 & 38.1 & 28.6 & 9.5 \\
\hline & & $\mathrm{No}=38.2$ & 23.1 & 15.4 & 15.4 & 46.2 \\
\hline \multirow{2}{*}{$\begin{array}{l}\text { Forced to have sex with } \\
\text { someone (including } \\
\text { intercourse, anal sex, } \\
\text { or oral sex) }\end{array}$} & \multirow[t]{2}{*}{0.5} & Yes $=27.3$ & 33.3 & 66.7 & 0 & 0 \\
\hline & & $\mathrm{No}=72.7$ & 37.5 & 12.5 & 25 & 25 \\
\hline
\end{tabular}

a. Based on 2,708 women being surveyed.

Table 3: Newly Reported Sexual Violence Cases in 2007 in Hong Kong

\begin{tabular}{lc}
\hline Types of Abuse & January to December 2007 \\
\cline { 2 - 2 } & $\mathrm{N}(\%)$ \\
\hline Rape & $90(11.3)$ \\
Indecent assault & $684(85.8)$ \\
Forced masturbation & $0(0.0)$ \\
Forced oral sex & $1(0.1)$ \\
Buggery & $0(0.0)$ \\
Others & $6(0.8)$ \\
Multiple incident & $16(2.0)$ \\
Total & $797(100.0)$ \\
\hline
\end{tabular}

Source: Statistics on cases involving sexual violence are captured by the Central Information System on Sexual Violence Cases by Social Welfare Department, the Government of Hong Kong.

forced to have sex (including intercourse, anal sex, or oral sex) by someone other than their spouse, with $27.3 \%$ of the victims reporting that the incidents happened at or before age 17 (see Table 2). Among the victims of forced sex taking place at or before age $17,66.7 \%$ reported the acts as being perpetrated by someone they knew, and $33.3 \%$ were forced to have sex by family members. These figures demonstrate that a considerable number of women were sexually abused at a very young age by people they knew and had trusted. The reported cases of sexual violence in Hong Kong, which numbered 704 in 2006, comprise only a very small proportion of the estimated total number of incidents of sexual violence, indicating that underreporting is likely to be particularly serious in the territory (see Table 3 ).

Sexual harassment in the workplace is particularly prevalent in Taiwan and the
Mainland. In Taiwan, approximately $26 \%$ of the women and $13 \%$ of the men reported experiencing sexual harassment in the workplace (Luo, 1996). The most frequently reported forms of sexual harassment were unwanted sexual jokes or comments, unwanted deliberate body contact, and pressure for a date. It is estimated that the incidence of sexual assault in Taiwan ranges from 7,000 to 10,000 per year, or 20 to 27 per day (Luo, 2000). In Mainland China, the prevalence of sexual harassment in the workplace varies from 5.5\% (Chan, Wang, \& Yin, 2003) to 63\% (Wang, 1998) and can even be $84 \%$ (Tin, 2003). Such great variation in rates is possibly owing to the different definitions of sexual harassment used in the different studies. In a recent large online survey conducted by Sina.com.cn on sexual harassment in the Mainland, $60 \%$ of the 8,282 respondents reported being sexually harassed. A recent study conducted by the All-China Women's Federation showed that approximately $70 \%$ of women respondents reported being sexually harassed, with $32 \%$ and $16 \%$ of them reportedly abused by their seniors and colleagues, respectively (Peng, 2005).

\section{Sexual Violence in Dating Relationships}

It has been reported that approximately one in every five women has experienced sexual violence in a dating relationship, and up to one third of women describe their first sexual experience as being forced (WHO, 2003). Sexual abuse in dating relationships has been the focus of a variety of studies. A Hong Kong-based 
study found that $20 \%$ of female university students had been reportedly forced to engage in some form of sexual contact in their lifetime by someone they knew, whereas 3\% had reported having been forced to have sex with their partner (Tang, Critelli, \& Porter, 1995).

In a more recent study on the prevalence of sexual coercion among dating partners, a sample of 651 students attending three universities in Hong Kong reported a lifetime and preceding-year prevalence of sexual coercion of $19.8 \%$ and $14.6 \%$, respectively (Chan, Brownridge, Leung, Tiwari, \& Hesta, 2008). Approximately $3 \%$ of the participants had reportedly suffered serious injury, of whom a high proportion were men. Male perpetrators reportedly caused higher rates of injury to partners than did female perpetrators. However, gender differences were not statistically significant with respect to the prevalence and frequency of sexual coercion. With regard to sexual coercion in Beijing and Shanghai, and in Hong Kong, $12.7 \%$ and $9.5 \%$, respectively, reported having sexually coerced their dating partner, whereas $15.4 \%$ and $13 \%$, respectively, said they had experienced sexual coercion from their dating partner (Chan \& Straus, 2005). Similar rates were found in Taiwan, where the overall prevalence of sexual abuse in dating relationships was $24.7 \%$ (Chen, 1996). Approximately $6.8 \%$ of the male students and $42.1 \%$ of the female students had reportedly experienced sexual abuse.

A survey on sexual victimization among 178 Chinese female college students found that $88.20 \%$ of the students had reportedly experienced verbal sexual assault, $42.36 \%$ unwanted physical approaches, and $0.56 \%$ to $11.80 \%$ different kinds of sexual coercion, of which $7.30 \%$ was rape or attempted rape ( $\mathrm{Xu}, \mathrm{Xie}, \&$ Chen, 1998). The rate of seeking help was extremely low among the victims. Only 18\% disclosed the episodes to their parents, and only $3.73 \%$ reported them to the police. Most victims apparently suffered silently without seeking any support, and most indicated they thought reporting would not bring any benefit but only shame. Some apparently did not even know they could report such matters to the police. None of the victims reportedly knew anything about the victim assistance program.

\section{Rape}

In Hong Kong, there are two sources for statistical information on reported rape and sexual assault. One is the social services that help victims of rape and sexual assault, such as the Family Planning Association of Hong Kong and the Association Concerning Sexual Violence Against Women. The figures provided by the Family Planning Association of Hong Kong have been declining because the service provision has shifted to Association Concerning Sexual Violence Against Women, which has been formally subsidized since 2002 . Combining the figures from the two agencies, the reported number of rape cases has been steady at approximately 200 per year. In 2002, a total of 217 rape cases were reported.

The second data source comes from the official crime statistics provided by the Hong Kong Police Force, which reported a total of 95 rape cases in 2002. At the same time, the Census and Statistics Department of the Government of Hong Kong, which conducts a periodic Crime and Victimization Survey concerning rape and sexual assault cases, reported 12,500 incidents in 1998. Thus, the figures provided by the Hong Kong Police Force suggest that the reporting rate of rape and sexual assault incidents in 1998 was 10\%, indicating that rape is a rarely reported event in contemporary Chinese societies such as Hong Kong.

Because there is no publicly released official crime record of rape and sexual assault incidents in Mainland China, it is difficult to estimate the incidence of rape or sexual assault in the Mainland.

\section{Child Sexual Abuse}

In a study of 2,147 Chinese university students in Hong Kong, 4.3\% of the men and $7.4 \%$ of the women reported experiencing one or more incidents of sexual violence before age 17. In less than one third of the cases, the perpetrators were strangers (Tang, 2002). In a more recent and representative population study, a household survey of parents' reports of incidents that had happened to their children found that $0.3 \%$ of children had been 
reportedly sexually harassed (i.e., had been forced to touch someone or had been touched in a sexual way), and $0.1 \%$ had been forced to have sex (total number of children in the sample = 2,081; Chan, 2005). Child sexual abuse (CSA) incidents are likely to be underreported because figures are collected based on parents' reports of known incidents.

The Child Protection Registry (CPR), under the aegis of the Social Welfare Department of the Government of Hong Kong, records reported cases of child abuse. In 2006, among the 806 reported child abuse cases, $28.9 \%$ involved sexual abuse.

Chen and associates (Chen, Dunne, \& Wang, 2002, 2003) conducted two surveys of high school students in Liaoning province in northeastern China and found that $25 \%$ of the girls and $23 \%$ of the boys reported at least some type of noncontact sexual event, including genital exposure, or their witnessing masturbation; $2.3 \%$ of the girls had reportedly experienced attempted vaginal penetration, whereas $5.8 \%$ said someone had touched or fondled their breasts or genitals before age 16 against their will. A later and larger-scale cross-sectional survey among a convenience sample of high school students in Beijing municipality (equivalent to a province), and in Hubei, Henan, and Hebei provinces (Chen, Dunne, \& Han, 2004) found that the prevalence of unwanted sexual experience before age 16 was reportedly higher among girls $(16.7 \%)$ than boys $(10.5 \%)$. Sexual penetration was rarely reported $(1 \%)$, whereas $7 \%$ reported at least one type of physical contact abuse (girls $8.9 \%$, boys $5.0 \%$ ). Male and female victims of CSA were more depressed and suicidal, and drank alcohol more often, than unaffected adolescents. Female victims were also more likely than others to engage in anorexic and bulimic behaviors, whereas male victims were more often involved in violence.

Studies have found that the prevalence of reported sexual violence and victimization among women seeking abortion in China is between $14 \%$ (Wu, Wang, Zhao, \& Zhang, 2006) and 18\% (Wu, Guo, \& Qu, 2005). Among the victims of reported sexual abuse, $8.6 \%$ had undergone their first sexual encounter in childhood, $42.7 \%$ had multiple sexual partners, and
$21.6 \%$ had never used contraception. The prevalence of reported sexual abuse is high in China and increases the risk of acquiring sexually transmitted diseases.

A low reporting rate for CSA has been noted by various researchers (Ho \& Mak, 1992; Ma, Yau, Ng, \& Tong, 2004; Ross et al., 2005). Family shame and the insensitivity of professionals have been suggested to account for the lack of disclosure; thus the low figure for reported incidents (Ho \& Kwok, 1991).

\section{Violence Against Sex Workers}

A sex industry exists but is not publicly acknowledged in Chinese societies, not even in cosmopolitan and modernized cities such as Hong Kong. Consequently, very few studies have focused on violence against sex workers. A cross-sectional survey of female sex workers in Hong Kong showed that they scored significantly lower on reported quality of life when compared with women working in nonsexual jobs. Sex workers were at risk of being abused while at work and had a higher level of exposure to both violence and discrimination. For example, they felt physically unsafe, and they reported cases of rape $(3.4 \%)$, beatings $(7.9 \%)$, or verbal abuse $(11.2 \%)$ by clients (Wong, Holroyd, Gray, \& Ling, 2006).

\section{Internet Sexual Violence}

Mitchell, Finkelhor, and Wolak (Mitchell, Finkelhor, \& Wolak, 2003a, 2003b, 2005; Mitchell, Wolak, \& Finkelhor, 2007) have published a series of papers on Internet crime against children, in particular, child pornography and sexual violence. This new form of sexual violence against children and adolescents deserves more attention. Chinese societies are no exception with regard to the increasing prevalence of this type of violence. There have also been studies of the recent increase in the number of incidents of sexual violence shown on the Internet as reported in the media. For instance, in June 2007, some nude photos of pop stars were posted on the Web without the female subjects' consent and circulated widely in Hong Kong; in June 2007, 
a female student in Macau was sexually abused, photos of which were posted online; photos of a member of the pop duo "Twins" taken when she was changing were published in a weekly magazine, and so on. In January 2008, photographs depicting a male actor engaging in sexual acts with several actresses were circulated on the Internet, which caused him and the actresses enormous damage. An increasing number of incidents of sexual violence involving handy cameras, video cameras, and the Web have also been reported. Victims are threatened with the uploading of photos or videos of themselves as a means of control. Only one study has been published looking at sexual violence on the Web, in which approximately $60 \%$ of respondents reported experiencing cybersexual violence. Significantly more women $(63.8 \%)$ than men $(51.7 \%)$ had been abused $(\mathrm{Ng}, 2004)$, although the figures for both sexes were high.

There are various types of sexual violence. A systematic review of the magnitude and types of sexual violence can help portray the outstanding issues and thus serve as a basis for future study aimed at reducing both the frequency of this behavior and the damage to the victims.

\section{RISK FACTORS FOR SEXUAL VIOLENCE}

Sexual violence is typically described as predominantly a power-based abuse of victims who are less privileged and/or powerful. Thus, women, children, and employees are the most likely potential victims, whereas men, parents or caretakers, and employers are the most likely potential abusers. The study of sexual violence in China is still in its infancy. Sexual violence is a specialized form of human violence, and this review includes studies of risk factors relating to intimate violence in general and sexual violence in particular. Brownridge et al. (2008) used a nested ecological framework for examining risk markers of violence to discuss the risk factors for sexual and intimate violence in Chinese societies. Risk markers for violence have been identified at multiple levels of the victims' environment. Accordingly, Brownridge et al. integrated into a nested ecological framework risk markers that have been applied to violence. Applying this framework to violence divides the environment into three levels: the ontogenic, the microsystem, and the macrosystem. The ontogenic level comprises the development of individuals and, as a result, what they bring to the other levels based on their development. It includes factors that influence the likelihood of men committing sexual assault or rape as well as factors that influence the vulnerability of women and children. The microsystem consists of the family or immediate setting in which the violence occurs, whereas the macrosystem includes the cultural values and attitudes that foster violence.

\section{The Ontogenic and Microsystem Levels}

Factors that increase men's risk of committing sexual violence against partners. In general, the demographic and socioeconomic characteristics of Chinese abusive partners have been found to be related to unemployment or a low socioeconomic status (Leung et al., 1999; Parish, Wang, Laumann, Pan, \& Luo, 2004; Xu et al., 2005; Yick, 2000); the abuse of alcohol and/or drugs (Liu \& Zhang, 2005; Parish et al., 2004; Xu et al., 2005); gambling problems (Liu \& Zhang, 2005); young age (Tang, 1999); a sense of insecurity, an aggressive personality, poor anger management, a lack of empathy (Chan, 2004); psychological disorders (Liu \& Zhang, 2005); and sexual jealousy (Parish et al., 2004).

The relationship risk factors for partner violence include relationship stress and conflict (Chan, 2004; Xu, 1997; Xu et al., 2005) as well as extramarital affairs (Liu \& Zhang, 2005; Xu et al., 2005). The rise of cross-border marriages has led to an increase in the rate of family violence, including spousal and child abuse. A large spousal age difference is prevalent among families in which a husband, usually aged more than 50, marries a young woman from Mainland China, and this was found to be a significant risk factor for violence. Family violence is frequent among couples with an age difference of 10 years or greater (Chan, 2005; Tang, 1999; Tiwari et al., 2007). It is reported 
that when a cross-border bride moves to Hong Kong after the marriage, she often finds that her husband's economic condition is not as good as she had been led to expect. Frequent marital conflicts and violence may be related to this discrepancy.

With regard to risk factors specific to sexual violence against partners, an aggressive behavioral style was found to be a predictor of sexual aggression (Tang, Critelli, \& Porter, 1993). Aggressive men tend to use more coercive methods to induce fear in their partners and exercise control over them (Wu et al., 2005). A recent study showed that a history of neglect from parents or caretakers was associated with sexual coercion in the dating relationships of students (Chan, Brownridge, et al., 2008). Family-of-origin habits that transferred rapesupporting attitudes to the new family appeared to carry over into dating relationships (Adams-Curtis \& Forbes, 2004). The findings also showed that perpetrators of sexual coercion had less stable mental health when compared with the nonperpetrating participants. This is consistent with findings in Western studies that sexual abusers with mental health problems are a high-risk group (Cosyns, 1999).

Factors related to the vulnerability of women and children. Certain studies have identified factors that increase the vulnerability of women and children to abuse, such as unplanned pregnancy (Leung et al., 1999), women in need of financial assistance (Tiwari et al., 2007), depression and somatic symptoms (Hicks \& Li, 2003; Yick, Shibusawa, \& Agbayani-Siewert, 2003), and poor psychological health (Leung et al., 2003). In one study of dating violence, physical violence, and sexual violence, victimization was associated with an increased rate of suicidal ideation and depression (Chan \& Straus, 2005).

A significant proportion of sexual abuse is committed by acquaintances of the victims (Chen, 1996) and persons with intrafamilial relationships; that is to say, the abusers are known to their victims. In addition, a gender difference exists in the type of sexual violence in Chinese societies. Males are about three times more likely than females to be sexually abused by their friends, whereas females are about twice as likely as males to be sexually abused by strangers (Tang, 2002). Twice as many women as men report having been sexually harassed (Tang et al., 1996).

Students who were subjected CSA reported higher levels of depression; lower levels of selfevaluated health; higher levels of drinking alcohol, smoking, and engaging in sexual intercourse; suicidal thinking and planning of suicide; receiving threats or injury by someone with a weapon such as a knife on school grounds; and involvement in a physical fight during the 12 months preceding the survey (Chen, Dunne, \& Han, 2006; Chen, Han, \& Dunne, 2004). Chinese women survivors of CSA often suffer some form of anxiety disorder or depressive disorder (Li, 1990), or trauma symptoms (Poon, 2007; Tsun-yin, 1998) and are at significantly increased risk of contracting sexually transmitted diseases (Wu et al., 2006).

Sexual abuse survivors may suffer from diminished self-esteem, disempowerment, fear for personal safety, a heightened sense of vulnerability to revictimization, or impairment of the ability to life effectively. Sexual stigmatization also reportedly reflects the patriarchal fetish for female chastity in the Chinese cultural construction of sexual victimization (Luo, 1998, 2000).

\section{Macrosystem Level}

The macrosystem level includes the cultural values and attitudes that foster violence. Patriarchal social forms have been reported to play an important role in violence (Liu, 1999). Within the family, men have been reported to use physical and/or psychological violence to exert a position of dominance over their partner or their children. Although existing studies address patriarchy as a risk factor for violence against women in general and do not specifically address it in terms of sexual violence, it is worth investigating as a possible risk factor in future studies of sexual violence in Chinese societies.

Patriarchal authority structures and violence against women. The lack of legal and social support for victims has been suggested to be an 
indication of the social isolation that makes it difficult for victims to disclose violence ( $\mathrm{Xu}$, 1997). This is particularly true for victims growing up in rural areas of China and for immigrants to cities (Xu et al., 2005). With regard to victims of spousal sexual violence, Liu (1999) argued that even though battered women have used divorce to end their abusive experience in many countries, it is uncommon for battered women in China to do so. Divorce has been strictly controlled by the government and less formally, by social norms, and battered women lack personal resources. Thus, enduring violence has reportedly become a main coping strategy for battered women in rural China.

The social and cultural acceptance of women's subordination is considered an important factor contributing to violence against them (Liu, 1999). Studies have reported patriarchal forms of authority and strong beliefs in patriarchal gender relationships to have significant correlations with spousal violence in Chinese populations (Chan, 2004; Liu \& Zhang, 2005; Parish et al., 2004; Xu et al., 2005). In Chinese culture, male dominance and patriarchal forms have been regarded as core family values and even treated as proverbs of life. They have even been reported to espouse traditional values and to hold on to the belief that there may be good reasons to beat a wife (Xu et al., 2005), especially as a way of preserving the "face" of the male partner (Chan, 2006). Chan (2006) found that abusers held a traditional gender role assumption that the man should be the provider and the woman the caregiver. To save face, there are men who reportedly believe they must dominate their wives. Cultural acceptance of wife abuse (Liu, 1999; Yick \& Agbayani-Siewert, 2000), and in particular, the lack of legislation defining family violence as illegal (Liu \& Zhang, 2005), force a victim of spousal violence to stay in the abusive relationship (Wu et al., 2005). Patriarchal forms affect the way that women cope and thus reinforce the patriarchal structure. A case study of rape in Mainland China (Gil \& Anderson, 1999) argued that rape was the victimization of a woman within the context of a patriarchal and phallocentric culture. Chinese women may be described as being similarly victimized by their subordinate position in a Chinese society that has been culturally and historically sustained by gender inequality.

In modern China (after 1949), the government of the People's Republic of China declared in a constitutional legal document that women should enjoy equal rights with men with respect to politics, economics, culture, education, and social life (Chen, 1999). But in reality, legal equality between men and women does not amount to true equality in practice (Liu, 1999; Xu, 1997). The patriarchal social order and family system have long been the entrenched pattern in economic and social processes in Chinese society. This has been widely reported to have resulted in the subordination of women and thus in the violence perpetrated against them. The government's ineffectiveness in combating domestic violence has been critical in this regard, in particular, the insensitivity of the criminal justice system to the illegal acts committed, insufficient laws combating violence against women, the lack of coordination between government departments in helping victims, and systematic failure in victim protection.

Poverty and sexual violence. The workplace is a reported site of sexual violence. Female workers are more vulnerable, in particular those who are poor, and also those who have come from rural areas and work in cities. They lack resources and social support. They also have no knowledge of the legal protection to which they are entitled. As Gil and Anderson (1999) stated, "Official law denounces rape, but there is no law, mechanism, or facilitation that provides women the means by which to resist. Moreover, there is no national teaching that corrects the social shaming inherently attached to sexual victimization." Even if women have legal protection against sexual violence, their deprivation because of poverty, unawareness of available legal resources, and lack of support mean that they are not, in fact, protected from sexual violence.

Culture-specific risk factors for CSA. The cultural belief that family problems should be 
kept strictly within the family may make disclosure even more difficult. Cultural factors, combined with the currently inadequate resources for victims, could be contributing to a double victimization (Rhind, Leung, \& Choi, 1999). Cultural aspects may heighten family disgrace and intensify the dangers of disclosure for the victim. Ho and Kwok (1991) detailed how features of the Chinese pattern of childrearing, from the principle of filial piety to that of unquestioning obedience, may facilitate the use of children by adults as sexual objects. They criticized the low level of awareness among professionals, which they felt might account for the apparently low incidence of reporting CSA.

This study has reviewed a number of universal and culture-specific risk factors for sexual violence in Chinese societies. Cultural beliefs, patriarchal authority, and poverty are cultural and social factors that have been reported to affect he occurrence of sexual violence and help-seeking behaviors. There remains room for future study on other risk factors related to the characteristics of sex offenders, families, and communities at high risk for sexual violence.

\section{COMMUNITY KNOWLEDGE AND PERCEPTIONS OF SEXUAL VIOLENCE}

\section{Recognizing Sexual Harassment}

In one study, 900 Chinese students demonstrated a high level of agreement in not regarding overt unwelcome physical contact and coercive sexuality as sexual harassment. Only a small percentage classified sexist and misogynistic behaviors, pressure for dates, and unsolicited disclosure of personal and emotional feelings as sexually harassing (Tang, Yik, Cheung, Choi, \& Au, 1995). In a study of 175 medical doctors working in emergency department in Hong Kong, 36\% agreed that "a woman should be responsible for preventing her own rape," and a majority of female doctors agreed that "a woman can successfully resist rape if she tries hard enough" (Wong, Wong, Lau, \& Lau, 2002). Such rape myths may contribute to a victim-blaming attitude.

\section{Reporting and Help-Seeking Behavior}

Chinese have been described in various studies as finding the reporting, and thus the disclosure of incidents of sexual violence, difficult. In a study of 2,147 Hong Kong Chinese college students, only $39 \%$ of victims had reported their sexual victimization to others, whereas $56 \%$ of the reported incidents were not followed up (Tang, 2002). The main reasons for not reporting an incident included low expectations concerning the outcome. For example, some victims thought that reporting would cause trouble, whereas others expected the police would be rude or would violate their confidentiality; some anticipated embarrassment, and others feared the offender's revenge would get them into trouble (Dussich, 2001) or had low expectations that the authorities would take an active role in combating the problem (Tang et al., 1996). In a recent study of 137 rape victims in Hong Kong, late presentation and poor attendance for follow-up care among rape victims was associated with complications such as pregnancy, sexually transmitted diseases, headaches, and psychological problems. Further delay made termination of pregnancy risky (Chu \& Tung, 2005). Embarrassment is a major reason that rape victims hesitate to seek medical care. Vulnerable groups such as female adolescents with mild mental retardation had the most difficulty in reporting a sexually abusive incident or the characteristics of the offender because of inadequate self-protection skills or inadequate knowledge of sexual abuse (Tang \& Lee, 1999).

Shame is known to be a particularly strong factor among Asian individuals in deterring them from seeking outside professional help (Lee \& Law, 2001). Generally, a perceived need to save face exerts an important influence on self-disclosure (Li, 1999). The importance of saving face is thus likely to strongly influence female victims, especially their help-seeking behavior after being abused. Chinese culture has been described as constructing a woman's identity as centering on her father, husband, and son in the context of Chinese hierarchical relationships (Pearson \& Leung, 1995). Chinese women reportedly define their success mainly 
through the well-being of their family, in particular that of their husband and son. The traditional emphasis on chastity results in women who have been raped as potentially being viewed as adulterous or having a bad reputation. The burden of strong physical resistance to an attacker is furthermore placed on the shoulders of the person being attacked (Tanner, 1994). Female victims have expressed feeling stressed that it would bring shame on their family if they were to disclose an abusive incident, and they therefore tend to remain silent. This is echoed by other studies that have found that the cultural values of suffering and fatalism interfere with help-seeking behavior. Even Asian Americans are reported to be more tolerant of abuse than other ethnic groups (MalleyMorrison \& Hines, 2004). Participation in sexual abuse programs is generally low because the feeling of shame resulting from CSA prevents victims from disclosing it to others. Among 1,606 Chinese adults in Hong Kong only $24 \%$ of victims indicated they would take part in CSA prevention programs (Tang \& Yan, 2004). The attitudes of Chinese parents are also very influential in approving school CSA prevention education (Chen \& Chen, 2005). Those who would not tolerate sexual violence were also more likely to support gender equality and flexible gender roles (Tang et al., 1995).

\section{CURRENT RESEARCH ON SEXUAL VIOLENCE IN CHINA}

\section{Diversity of Findings and Study Methods}

Studies of the prevalence of and risk factors for sexual violence have used a diverse range of samples and research methods. Samples have been taken from among Mainland Chinese, Hong Kong Chinese, and Taiwanese, and a few from Chinese immigrants. These studies have employed an epidemiological methodology to look at the prevalence and correlations of sexual violence, and an anthropological methodology to look at the risk factors causing the problems. Some studies have used questionnaires, focus group interviews, and case studies to collect data, and so the measurement instruments employed are not consistent. Some have used standardized measures such as the Conflict Tactics Scales (CTS; Straus, 1979), its revised version (CTS2; Straus, Hamby, Boney-McCoy, \& Sugarman, 1996), and the Chinese Abuse Assessment Screen (Tiwari et al., 2007). Faceto-face interviews (Chan, 2006; $\mathrm{Xu}$ et al., 2005) and telephone surveys (Tang, 1999; Yick, 1999, 2000) have mostly been used to ask respondents about their personal experiences of violence.

Very few studies have used probability samples (Chan, 2005). Most of them have surveyed convenience samples that could be easily obtained or were connected in some way to the investigators. Although some have focused on young populations like college students, others have targeted populations covering a wide age range. Sample sizes have also varied, from less than a hundred in small-scale studies to a few thousand in representative studies. Samples from health settings and refugee services have mainly included women seeking help and treatment as a result of abuse, and so studying them would undoubtedly yield generally higher prevalence rates. Samples such as school students may be more likely to represent the pattern of population.

Currently, the data on sexual violence typically come from cases reported to the police and incidents revealed in clinical settings and surveys. A substantial number of victims are still unknown to the system. The diversity of findings reported by surveys and criminal reports reflects the problems in obtaining accurate figures on the scope of the problem. The problem of underreporting for multifaceted reasons makes estimating the true prevalence very difficult, and the available figures very likely show only the tip of the iceberg. Whereas resources are mostly allocated to treat reported cases, a closer look at available survey findings may help the government appreciate the urgency in filling the gap between the needs of victims and the existing services available to them.

In future studies of sexual violence in Chinese societies, probability samples recruited by random sampling could be used to compare the prevalence rates and risk factors with those of other ethnic groups and between different Chinese communities. Standardized questionnaires, rather than self-constructed 
ones, should be used as the basic measurement of violence.

\section{Interpretation of Chinese Culture-Specific Risk Factors}

The Chinese are a diversified population spread across many different societies. The Chinese population includes Chinese immigrants in Western societies and those living in Mainland China, Hong Kong, Macau, and Taiwan. Most Chinese live in predominantly Chinese societies such as Mainland China, Hong Kong, Macau, and Taiwan. As discussed at the beginning of this article, these societies differ in terms of their sociopolitical-economic structures. Thus, interpretation of culture-specific risk factors should be undertaken cautiously. One intriguing question is whether these factors might be protective factors. For example, filial piety has been treated as risk factor for family violence (Malley-Morrison \& Hines, 2004), although it is difficult to understand how such a virtue could be a risk factor associated with violence. However, other scholars have treated filial piety as a protective factor against family conflict and other problems (Lee \& Mjelde-Mossey, 2004). Discussions of culture-specific factors to date have tended to be too general and lack empirical support. As it is highly likely that cultural factors do play an important role, it is important that they be investigated in a more systematic and rigorous manner.

\section{Chinese Culture: Culture of Harmony or Culture of Violence?}

Chinese people have been reported to relate to others by first defining their relationships based on their cultural norms. Authoritarianism has been indicated to be one of the main guiding parameter for Chinese people in relating to each other. It emphasizes filial piety-that "juniors and seniors have their ranking," as one Chinese proverb puts it-and Chinese people are oriented toward finding their proper place in the hierarchy (Bond, 1991, p. 36).

One Chinese sociologist, Fei Xiao-tong (1947), proposed the concept of "compartmentalization of the relationship network" to understand the relationship between self and others. According to Fei (1947), family, including one's wife and children, is the first compartment next to the "self." Although it would seem that Fei's argument could apply to all Chinese individuals, including men and women, the woman does not posit herself at the center but instead subordinates herself to her family and her husband. In the Chinese tradition, the woman does not engage in a powerful position but has to obey her father, husband, and son. As one Chinese saying puts it, "A husband sings, the wife hums along" (Bond, 1991, p. 45). The husband to wife relation is defined as a hierarchical one. The man is usually dominant in the family and inherits the family property. The gender-role socialization of boys and girls is very different. Boys are socialized to take over power and responsibility, whereas girls are subject to subordination to men and to other women in the family hierarchy. The masculine stereotype is often associated with a sense of superiority, whereas the female stereotype is associated with a sense of inferiority (Cheung, 1996). Therefore, when referring to the family, the reference is usually to the man, who is the master of the family. Family needs are typically defined in terms of the man's needs, which are regarded as having top priority.

Traditional Chinese culture has been described as so tolerant of violence at home that violence of all kinds against women, even their killing, is culturally acceptable (MalleyMorrison \& Hines, 2004). But this ignores the effects of the legal system in modern society. Such tolerance may be partially true with regard to minor violence, control, psychological abuse, help-seeking behavior, and professional practice but not necessarily with regard to severe violence. This leaves open the question of the extent to which Chinese people, living in modern societies with the benefits of all the advances in economic, political, and legal development hold on to traditional beliefs. The interaction between traditional culture and modernity in the field of education and legal measures should be addressed in future studies. If domestic violence is criminalized, there will be no room to argue that violence is 
acceptable. However, culture may be influential in defining what kinds of violence are criminalized and the extent to which legal actors can use discretion with regard to arresting or charging perpetrators.

The study of culture-specific factors should not focus solely on cultural factors but should also examine traditional culture in the context of coming into contact with and hence being changed by modern society. Moreover, research should also address the way perpetrators use cultural values as an excuse to justify their violence and how this might be overcome as well as the impact of cultural beliefs on the help-seeking behavior of victims, such that help can be made more readily available.

\section{RECOMMENDATIONS FOR FUTURE RESEARCH ON SEXUAL VIOLENCE}

\section{Large Epidemiological Study}

As pointed out above, epidemiological data on sexual violence in China are by no means either rare or marginal. However, only a few studies have used probability sampling. A large epidemiological study on the prevalence and annual incidence of various types of sexual violence is urgently needed to estimate the seriousness of the problem, to examine the risk factors, and thus to inform the prevention of, and intervention in, sexual violence in China. The author and associates will be conducting a large epidemiological study specifically on CSA in China funded by the UBS Optimus Foundation, which is a philanthropic organization established by the Swiss bank UBS in 1999. This study will collect data on the prevalence and annual incidence of CSA, comprising official as well as community epidemiological data. This sort of study is timely and can help document the national data on sexual violence.

\section{Establishment of Official Data}

No official data on the incidence of sexual violence are published by the government in Mainland China. The Hong Kong Police Force publishes an annual report on the incidence of indecent assault and rape in Hong Kong, whereas social services organizations publish information on reported cases of various types of sexual violence. No crime victimization survey is available for reporting trends in sexual violence victimization. If we are to better understand the pattern of sexual violence in China, the government must first establishand it must be urged to establish - a data system to collect reported incidents. A community profile of sexual violence victimization must also be developed.

\section{Consistency in Defining Terms}

The terms rape, sexual assault, sexual abuse, and sexual violence have overlapping meanings and are thus frequently used interchangeably in reports and documents. However, they are used inconsistently. In some cases, sexual violence or assault is understood to involve rape, sexual harassment (Luo, 1996, 2000), or both (Chan, 2005). Some documents specify the relationship of the perpetrator to the victim, whereas others describe the victimization more generally. Even the calculation of the number of incidents and prevalence rates may be presented in a confused way. It seems to be a general phenomenon in the literature on domestic violence that using a time frame to distinguish incidence and prevalence has been the main thrust of the overcoming conceptual confusion (Brownridge \& Halli, 1999). There is a need to standardize or at least to define terms systematically in each study for accurate comparison. Measurement of the incidence of sexual violence is not standardized either. In particular, only a few studies have demonstrated the validation of measures in a Chinese population. Validation of selfconstructed or translated scales should be demonstrated in future studies of sexual violence in China.

\section{CONCLUSION}

This article has endeavored to provide a comprehensive review of the reported sexual violence against women and children in China 
and to provide researchers with information about strategies for conducting further research on this important subject. Different study methods (e.g., household, school, phone, mail, online interviews) have different strengths and limitations. Among the available methods, household interviews, although more expensive and complicated, have greater potential for producing a representative sample, with a high response rate and collection of more in-depth information related to the themes of the study. In studying CSA in China, we will employ household interviews for the purpose of establishing its prevalence and chronicity. The findings of the study will serve as a baseline for the reported incidence in the Mainland, and it will contribute to developing a surveillance system that will be used to track China's progress in dealing with cases of sexual abuse.

In terms of conducting social research, the Chinese government is more open than previously to supporting studies related to social problems. We do believe we will be given sufficient latitude to design our study independently, and we sincerely hope that more research on sexual violence in China in the near future will lead to greater understanding and a proper response to a pressing social and cultural issue.

\section{REFERENCES}

Adams-Curtis, L. E., \& Forbes, G. B. (2004). College women's experiences of sexual coercion: A review of cultural, perpetrator, victim, and situational variables. Trauma, Violence, \& Abuse, 5, 91-122.

Bond, M. H. (1991). Beyond the Chinese face: Insights from psychology (1st ed.). Hong Kong: Oxford University Press (China).

Brownridge, D. A., Chan, K. L., Hiebert-Murphy, D., Ristock, J., Tiwari, A., Leung, W. C., et al. (2008). The elevated risk for non-lethal post-separation violence in Canada: A comparison of separated, divorced and married women. Journal of Interpersonal Violence, 23, 117-135.

Brownridge, D. A., \& Halli, S. S. (1999). Measuring family violence: The conceptualization and utilization of prevalence and incidence rates. Journal of Family Violence, 14, 333-350.

Chan, C. F., Wang, S. C., \& Yin, C. S. (2003). Study of workplace violence in two hospitals in Guangzhou (in Chinese). Chinese Journal of Preventive Medicine, 5, 358-360.

Chan, K. L. (2004). Correlates of wife assault in Hong Kong Chinese families. Violence and Victims, 19, 189-201.
Chan, K. L. (2005). Study on child abuse and spouse battering: Report on findings of household survey [A Consultancy Study Commissioned by the SWD of the HKSAR]. Hong Kong: Department of Social Work \& Social Administration, the University of Hong Kong.

Chan, K. L. (2006). The Chinese concept of face and violence against women. International Social Work, 49(1), 65-73.

Chan, K. L., Brownridge, D. A., Leung, W. C., Tiwari, A., \& Hesta, W. Y. H. (2008). Mental health profile of sexual violence perpetrators among university students in Hong Kong. In J. K. Quinn \& I. G. Zambini (Eds.), Family relations: 21st century issues and challenges (pp. 57-70). New York: Nova Publishers.

Chan, K. L., \& Straus, M. A. (2005). Prevalence of dating partner violence and suicidal ideation among male and female university students worldwide. Paper presented at the 9th International Family Violence Research Conference.

Chan, K. L., Tiwari, A., Fong, D. Y. T., Leung, W. C., Brownridge, D. A., \& Ho, P. C. (2008). Correlates of inlaw conflict and intimate partner violence against Chinese pregnant women in Hong Kong. Journal of Interpersonal Violence.

Chen, J., Dunne, M. P., \& Han, P. (2004). Child sexual abuse in China: A study of adolescents in four provinces. Child Abuse and Neglect, 28, 1171-1186.

Chen, J., Dunne, M. P., \& Han, P. (2006). Child sexual abuse in Henan province, China: Associations with sadness, suicidality, and risk behaviors among adolescent girls. Journal of Adolescent Health, 38, 544-549.

Chen, J., Dunne, M. P., \& Wang, X. (2002). Prevalence of childhood sexual abuse among female students in a senior high school. Chinese Journal of School Health, 23, 108-110.

Chen, J., Dunne, M. P., \& Wang, X. (2003). Childhood sexual abuse: An investigation among 239 male high school students. Chinese Mental Health Journal, 17, 345-347.

Chen, J., Han, P., \& Dunne, M. P. (2004). Child sexual abuse: A study among 892 female students of a medical school. Chinese Journal of Pediatrics, 42(1), 39-43.

Chen, J. Q., \& Chen, D. G. (2005). Awareness of child sexual abuse prevention education among parents of Grade 3 elementary school pupils in Fuxin City, China. Health Education Research, 20, 540-547.

Chen, M. (1999). From legal to substantive equality: Realizing women's rights by action. Violence Against Women, 5, 1394-1410.

Chen, R. (1996). Risk factors of sexual abuse among college students in Taiwan. Journal of Interpersonal Violence, 11, 79-93.

Cheung, F. M. (1996). Gender role development. In S. Lau (Ed.), Growing up the Chinese way: Chinese child and adolescent development (45-67). Hong Kong: The Chinese University Press.

Chiu, M. C. (2001). Politicizing Han-Chinese masculinities: A plea for court mandated counselling for wife abusers in Hong Kong. Feminist Legal Studies, 9(1), 3-27. 
Chu, L. C., \& Tung, W. K. (2005). The clinical outcome of 137 rape victims in Hong Kong. Hong Kong Medical Journal (Xianggang yi xue za zhi) / Hong Kong Academy of Medicine, 11, 391-396.

Cosyns, P. (1999). Treatment of sexual abusers in Belgium. Journal of Interpersonal Violence, 14, 396-410.

Dussich, J. P. J. (2001). Decisions not to report sexual assault: A comparative study among women living in Japan who are Japanese, Korean, Chinese, and English-speaking. International Journal of Offender Therapy and Comparative Criminology, 45, 278-301.

Fei, X. T. (1947). Rural China (in Chinese). Hong Kong: Joint Publishing.

Gil, V. E., \& Anderson, A. F. (1999). Case study of rape in contemporary China: A cultural-historical analysis of gender and power differentials. Journal of Interpersonal Violence, 14, 1151-1171.

Hicks, M. H., \& Li, Z. (2003). Partner violence and major depression in women: A community study of Chinese Americans. Journal of Nervous and Mental Disease, 191, 722-729.

Ho, T. P., \& Kwok, W. M. (1991). Child sexual abuse in Hong Kong. Child Abuse and Neglect, 15, 597-600.

Ho, T. P., \& Mak, F. L. (1992). Sexual abuse in Chinese children in Hong Kong: A review of 134 cases. Australian and New Zealand Journal of Psychiatry, 26, 639-643.

Krug, E. G., Dahlberg, L. L., Mercy, J. A., Zwi, A. B., \& Lozano, R. (Eds.). (2002). World report on violence and health. Geneva, Switzerland: World Health Organization.

Lee, M. Y., \& Law, P. F. M. (2001). Perception of sexual violence against women in Asian American communities. Journal of Ethnic and Cultural Diversity in Social Work, 10(2), 1-25.

Lee, M. Y., \& Mjelde-Mossey, L. (2004). Cultural dissonance among generations: A solution-focused approach with East Asian elders and their families. Journal of Marital and Family Therapy, 30, 497-513.

Leung, T. W., Ng, E. H. Y., Leung, W. C., \& Ho, P. C. (2003). Intimate partner violence among infertile women. International Journal of Gynecology and Obstetrics, 83, 323-324.

Leung, W. C., Leung, T. W., Lam, Y. Y., \& Ho, P. C. (1999). The prevalence of domestic violence against pregnant women in a Chinese community. International Journal of Gynecology and Obstetrics, 66, 23-30.

Li, C. L. S. D. (1999). Face orientation and self-disclosure of ability and morality: Does gender make a difference? Unpublished doctoral dissertation, The University of Hong Kong, Hong Kong.

Li, M. Y. (1990). Child sexual abuse in West China. American Journal of Psychiatry, 147, 258.

Li, Y. M. (2002). Legal review on marital rape (In Chinese). Contemporary Law Review, 9, 91-93.

Liu, M. (1999). Enduring violence and staying in marriage: Stories of battered women in rural China. Violence Against Women, 5, 1469-1492.
Liu, M., \& Zhang, L. (2005). Personal experiences and public attitudes: Findings from the national survey. In L. Huang \& W. Rong (Eds.), Combating domestic violence against women: China in action (pp. 125-142). Beijing: China Social Sciences Press.

Luo, T. Y. (1996). Sexual harassment in the Chinese workplace: Attitudes toward and experiences of sexual harassment among workers in Taiwan. Violence Against Women, 2, 284-301.

Luo, T. Y. (1998). Sexual abuse trauma among Chinese survivors. Child Abuse and Neglect, 22, 1013-1026.

Luo, T. Y. (2000). "Marrying my rapist?!": The cultural trauma among Chinese rape survivors. Gender $\mathcal{E}$ Society, 14, 581-597.

Ma, E. Y. M., Yau, D. C. W., Ng, W. W., \& Tong, S. L. (2004). Characteristics of child sexual abuse cases referred for psychological services in Hong Kong: A comparison between multiple incidents versus single incident cases. Journal of Child Sexual Abuse, 13(2), 21-39.

Malley-Morrison, K., \& Hines, D. A. (2004). Family violence in a cultural perspective: Defining, understanding, and combating abuse. Thousand Oaks, CA: Sage.

Mitchell, K. J., Finkelhor, D., \& Wolak, J. (2003a). The exposure of youth to unwanted sexual material on the Internet: A national survey of risk, impact, and prevention. Youth \& Society, 34, 330-358.

Mitchell, K. J., Finkelhor, D., \& Wolak, J. (2003b). Victimization of youths on the Internet. Journal of Aggression, Maltreatment and Trauma, 8(1-2), 1-39.

Mitchell, K. J., Finkelhor, D., \& Wolak, J. (2005). The Internet and family and acquaintance sexual abuse. Child Maltreatment, 10(1), 49-60.

Mitchell, K. J., Wolak, J., \& Finkelhor, D. (2007). Trends in youth reports of sexual solicitations, harassment and unwanted exposure to pornography on the Internet. Journal of Adolescent Health, 40, 116-126.

$\mathrm{Ng}, \mathrm{W}$. C. (2004). Study of cybersexual violence. Association Concerning Sexual Violence Against Women.

Parish, W. L., Wang, T., Laumann, E. O., Pan, S., \& Luo, Y. (2004). Intimate partner violence in China: National prevalence, risk factors and associated health problems. International Family Planning Perspectives, 30, 174-181.

Pearson, V., \& Leung, B. K. P. (Eds.). (1995). Women in Hong Kong. Hong Kong: Oxford University Press (China).

Peng, J. (2005). On protecting women's sexual rights (In Chinese). Presentday Law Science, 6, 68-72.

Poon, M. W. L. (2007). The value of using hypnosis in helping an adult survivor of childhood sexual abuse. Contemporary Hypnosis, 24(1), 30-37.

Rhind, N., Leung, T., \& Choi, F. (1999). Child sexual abuse in Hong Kong: Double victimization? Child Abuse and Neglect, 23, 511-517.

Ross, C. A., Keyes, B. B., Xiao, Z., Yan, H., Wang, Z., Zou, Z., et al. (2005). Childhood physical and sexual abuse in China. Journal of Child Sexual Abuse, 14(4), 115-126. 
Si, L. L. (2003). Violence against women: Inadequacies of legal protection (In Chinese). People's Congress Studying, 7, 25-27.

Soeken, K. L., McFarlane, J., Parker, B., \& Lominack, M. C. (1998). The abuse assessment screen: A clinical instrument to measure frequency, severity, and perpetrator of abuse against women. In J. Campbell (Ed.), Empowering survivors of abuse: Health care for battered women and their children (pp. 195-203). Thousand Oaks, CA: Sage.

Stith, S. M., \& Straus, M. A. (1995). Understanding partner violence: Prevalence, causes, consequences, and solutions. Minneapolis, MN: National Council on Family Relations.

Straus, M. A. (1979). Measuring intrafamily conflict and violence: The Conflict Tactics (CT) Scales. Journal of Marriage and the Family, 41(1), 75-88.

Straus, M. A., Hamby, S. L., Boney-McCoy, S., \& Sugarman, D. B. (1996). The Revised Conflict Tactics Scales (CTS2): Development and preliminary psychometric data. Journal of Family Issues, 17, 283-316.

Straus, M. A., Hamby, S. L., Boney-McCoy, S., \& Sugarman, D. B. (1999). The personal and relationships profile (PRP). Family Research Laboratory, Unpublished manuscript, Durham, NH.

Tang, C. S. K. (1999). Wife abuse in Hong Kong Chinese families: A community survey. Journal of Family Violence, 14, 173-191.

Tang, C. S. K. (2002). Childhood experience of sexual abuse among Hong Kong Chinese college students. Child Abuse and Neglect, 26(1), 23-37.

Tang, C. S. K., Critelli, J. W., \& Porter, J. F. (1993). Motives in sexual aggression: The Chinese context. Journal of Interpersonal Violence, 8, 435-445.

Tang, C. S. K., Critelli, J. W., \& Porter, J. F. (1995). Sexual aggression and victimization in dating relationships among Chinese college students. Archives of Sexual Behavior, 24(1), 47-53.

Tang, C. S. K., \& Lee, Y. K. S. (1999). Knowledge on sexual abuse and self-protection skills: A study on female Chinese adolescents with mild mental retardation. Child Abuse and Neglect, 23, 269-279.

Tang, C. S. K., \& Yan, E. C. W. (2004). Intention to participate in child sexual abuse prevention programs: A study of Chinese adults in Hong Kong. Child Abuse and Neglect, 28, 1187-1197.

Tang, C. S. K., Yik, M. S. M., Cheung, F. M. C., Choi, P. K., \& Au, K. C. (1995). How do Chinese college students define sexual harassment? Journal of Interpersonal Violence, 10, 503-515.

Tang, C. S. K., Yik, M. S. M., Cheung, F. M. C., Choi, P. K., \& Au, K. C. (1996). Sexual harassment of Chinese college students. Archives of Sexual Behavior, 25, 201-215.

Tanner, H. (1994). Chinese rape law in comparative perspective. Australian Journal of Chinese Affairs, 31, 1-23.
Tin, Y. (2003). Law and sexual harassment (In Chinese). Line of Vision, 6, 12-15.

Tiwari, A., Fong, D. Y. T., Chan, K. L., Leung, W. C., Parker, B., \& Ho, P. C. (2007). Identifying intimate partner violence: Comparing the Chinese Abuse Assessment Screen with the Chinese Revised Conflict Tactics Scales. BJOG, 114, 1065-1071.

Tsun-yin, E. L. (1998). Sexual abuse trauma among Chinese survivors. Child Abuse and Neglect, 22, 1013-1026.

Wang, X. (1998). Review of sexual harassment research. Collection of Women's Studies, 3, 39-44.

Wong, A. Y. S., Wong, T. W., Lau, P. F., \& Lau, C. C. (2002). Attitude towards rape among doctors working in the emergency department. European Journal of Emergency Medicine: Official Journal of the European Society for Emergency Medicine, 9(2), 123-126.

Wong, W. C. W., Holroyd, E. A., Gray, A., \& Ling, D. C. (2006). Female street sex workers in Hong Kong: Moving beyond sexual health. Journal of Women's Health, 15, 390-399.

World Health Organization. (2000). Multicountry study on women's health and life experiences questionnaire (Version 9). Geneva, Switzerland: Author.

World Health Organization. (2003). Guidelines for medicolegal care for victims of sexual violence. Geneva, Switzerland: Author.

Wu, J., Guo, S., \& Qu, C. (2005). Domestic violence against women seeking induced abortion in China. Contraception, 72(2), 117-121.

Wu, J., Wang, L., Zhao, G., \& Zhang, X. (2006). Sexual abuse and reproductive health among unmarried young women seeking abortion in China. International Journal of Gynecology and Obstetrics, 92, 186-191.

Xu, S., Xie, L., \& Chen, M. (1998). A survey of sexual victimization among 178 Chinese female college students. International Medical Journal, 5(2), 113-117.

Xu, X. (1997). The prevalence and determination of wife abuse in urban China. Journal of Comparative Family Studies, 28, 280-303.

Xu, X., Zhu, F., O'Campo, P., Koenig, M. A., Mock, V., \& Campbell, J. (2005). Prevalence of and risk factors for intimate partner violence in China. American Journal of Public Health, 95(1), 78-85.

Yick, A. G. (1999). Domestic violence in the Chinese American community: Cultural taboos and barriers. Family Violence and Sexual Assault Bulletin, 15(4), 16-23.

Yick, A. G. (2000). Predictors of physical spousal/intimate violence in Chinese American families. Journal of Family Violence, 15, 249-267.

Yick, A. G., \& Agbayani-Siewert, P. (2000). Dating violence among Chinese American and White students: A sociocultural context. Journal of Multicultural Social Work, 8(1-2), 101-129.

Yick, A. G., Shibusawa, T., \& Agbayani-Siewert, P. (2003). Partner violence, depression, and practice implications 
with families of Chinese descent. Journal of Cultural Diversity, 10(3), 96-104.

Ko Ling Chan, PhD, is associate professor of social work at the University of Hong Kong. He has established his expertise in the area of family violence and has conducted researches including the impact of family violence on battered women and their children; narrative accounts of male batterers; pregnancy and violence; international dating violence study etc. He completed a research project commissioned by the Hong Kong Government to study the prevalence rates and the risk factors of spousal and child abuse in Hong Kong, to review the legislative measures and to validate the risk assessment tool. He has developed an indigenous model of explaining Chinese men who batter their wives. The model employs Chinese concepts of face to explain the development of Chinese masculinity. He is directing a study of child sexual abuse in China. 